\title{
Key Issues and Trends of Postcolonial Feminism
}

\author{
A. V. Milto ${ }^{1}$
}

${ }^{1}$ Financial University under the Government of the Russian Federation, 12a Cooperative Street, Yaroslavl 150003, Russian Federation

DOI: $10.18255 / 1996-5648-2021-4-516-525$

Research article Full text in Russian

Postcolonial feminism is a response to Western Eurocentric feminism, which did not pay attention to racial differences, feelings and the position of women in the once colonized territories. The search for gender justice has led to the emergence of new theories and models reflecting the problems of oppression of women in the Afro-Asian world. The feminism of the postcolonial wave has focused on the issues of women's political participation, the preservation of patriarchal survivals in the family and the state, economic and social inequality, the impact of globalization and integration processes on the position of women in society. The lack of unity regarding the assessment of the influence of Western culture on traditional societies and the position of women in postcolonial countries has led to the emergence of many approaches to the interpretation of gender processes and the role of women in the modern world. An analysis of the variants of postcolonial feminism such as: womanism, stiwanism, motherism, nego-feminism and others allows us to draw conclusions about their engagement in global or national practice.

Keywords: Postcolonialism; Feminism; Gender; G. C. Spivak; C. Mohanty; Discrimination; Oppression; Wumanism; Globalization

\section{INFORMATION ABOUT AUTHORS}

\author{
Milto, Anna V. | E-mail: amilto@mail.ru \\ Cand. Sc. (History), Associate Professor
}




\title{
Ключевые проблемы и направления постколониального феминизма
}

\author{
А. В. Мильто ${ }^{1}$
}

${ }^{1}$ Финансовый университет при Правительстве Российской Федерации, ул. Кооперативная, дом 12a, Ярославль, 150003, Российская Федерация

DOI: 10.18255/1996-5648-2021-4-516-525

Удк 94(5)+94(6):396

Научная статья

Полный текст на русском языке

Постколониальный феминизм возник в ответ на западный евроцентричный феминизм, который игнорировал расовые различия, чувства и положение женщин на некогда колонизированных территориях. Поиск гендерной справедливости привел к появлению новых теорий и моделей, отражающих проблемы угнетения женщин в афро-азиатском мире. В центре внимания феминизма постколониальной волны оказались вопросы женского политического участия, экономического и социального неравенства, влияния процессов глобализации и интеграции на положение женщин в обществе. Отсутствие единства в отношении оценки влияния западной культуры на традиционные общества и положение женщин в постколониальных странах обусловило появление множества подходов к интерпретации гендерных процессов и роли женщины в современном мире. Анализ вариантов постколониального феминизма, таких как вуманизм, стиунизм, материзм, него-фреминизм и другие, позволяет сделать выводы об их ангажированности в глобальной или национальной практике.

Ключевые слова: постколониализм; фреминизм; гендер; Г. Ч. Спивак; Ч. Моханти; дискриминация; угнетение; вуманизм; глобализация

\section{ИНФОРМАЦИЯ ОБ АВТОРАХ}

Мильто, Анна Валентиновна $\mid$ E-mail: amilto@mail.ru

Кандидат исторических наук, доцент

В истории феминистского движения принято выделять три волны. Феминизм первой волны ассоциируется с деятельностью суфражисток, выступавших за права женщин в образовательной, социальной, политической сорерах в конце XIX - начале XX в. Вторая волна, зародившаяся в 1960-е гг., сосредоточилась на стремлении женщин к равенству с мужчинами в трудовой деятельности, семье, в сексуальном плане. Феминизм третьей волны, начавшийся в 80-е гг. XX в., шире обозначил круг актуальных для женщин 
Мильто А. В.

проблем и интересов, подчеркнув культурное, социальное, религиозное, национальное и сексуальное разнообразие, которое определило отсутствие единства в целях, моделях гендерных особенностей и предполагаемых способах изменения общества среди приверженцев данной теории.

Феминизм первой и второй волны в большинстве своем учитывал взгляды и потребности белых, гетеросексуальных и довольно обеспеченных женщин, живущих в промышленно развитых странах. Обращение к гендерным проблемам, затрагивающим вопросы культурной и этнической идентичности, расизма, политических, экономических и социальных последствий колониального воздействия на положение небелых женщин в бывших колониях Азии и Африки, состоялось в рамках третьей волны феминизма и стало неотъемлемой частью постколониальных исследований [1]. Постколониальный феминизм охватил вопросы женского политического участия, экономического и социального неравенства, влияния процессов глобализации и интеграции на положение женщин в обществе [2, р. 94].

Гендерные процессы, происходившие в афро-азиатском мире, долгое время отождествлялись с вестернизацией, заимствованием чужих ценностей и опыта, имитацией инородных форм общественно-политического и экономического развития. Универсальный образ женщины образованной, идущей в ногу со временем, способной принимать решения и обладающей свободой распоряжаться собственным телом, растиражированный в литературе, искусстве, средствах массовой инорормации, отразил преимущественно перспективу белых западных женщин среднего класса. Опыт небелых женщин, традиционно воспринимавшихся в качестве зависимых и подчиненных, пассивных и безгласных, игнорировался, как несоответствующий критерию восприятия гендерного развития общества.

Женщины, не подходившие под заданные установки, чувствовали себя незаметными, невидимыми, поскольку не были должным образом представлены в женском движении. Оценивая гендерные теории, идеологи постколониального феминизма, такие как Г. Ч. Спивак ${ }^{1}$, В. Шива ${ }^{2}$, Ч. Мохан-

\footnotetext{
${ }^{1}$ Гаятри Чакраворти Спивак (род. в 1942 г.) - профессор гуманитарных наук Колумбийского университета родом из Индии; один из идеологов постколониальной теории. Получила степень бакалавра в Калькуттском университете (1959 г.) и степень доктора наук по сравнительному литературоведению в Корнеллском университете (1967 г.). Обладательница двенадцати почетных докторских степеней. Ее эссе «Могут ли угнетенные говорить?» считается мировой классикой постколониальных исследований. Входит в число экспертов Всемирного экономического форума.

${ }^{2}$ Вандана Шива (род. в 1952 г.) - индийский философ, антиглобалист и экофеминист. Проживает в Дели, является автором более 20 книг и более 500 статей в ведущих научных и технических журналах. Удостоена Азиатской премии культуры Фукуока (2012г.) и «За правильный образ жизни» в 1993 г., MIDORI Prize (2016).
} 
ти ${ }^{3}$, Л. Ганди ${ }^{4}$, Р. Чау ${ }^{5}$, Э. Уокер ${ }^{6}$, О. Огундипе-Лесли ${ }^{7}$, О. Немека ${ }^{8}$ и другие, продемонстрировали неприятие западного (белого) феминизма, критикуя его за обобщение проблем и игнорирование интересов женщин афро-азиатского мира. Они отвергли предположение о том, что белых женщин из среднего класса следует считать нормой, утверждая, что их трудности не обязательно касаются всех женщин и что различия в социальном положении порождают очень разные проблемы и способы их решения.

Сторонницы постколониального феминизма выдвинули тезис, что равенство для белой женщины среднего класса в США и, например, мусульманской женщины в Иране выглядит по-разному. Так, постколониальный феминизм вышел за рамки западных представлений о гендерном равенстве, чтобы понять и интерпретировать повседневный жизненный опыт разных национальных, этнических и религиозных слоев.

Гаятри Ч. Спивак - одна из основательниц постколониального подхода - гендерные вопросы рассматривала в рамках проблем существования и самовыражения субалтернов - «угнетенных»9. В работе «Французский феминизм в интернациональной оправе» [3] она подняла вопрос о несоответствии западных приоритетов интересам и заботам жительниц бывших

3 Чандра Талпаде Моханти (род. в 1955 г.) - американский социолог индийского происхождения, заслуженный профессор женских и гендерных исследований, декан-профессор гуманитарных наук Сиракузского университета (штат Нью-Йорк). Выступала за включение транснационального подхода в изучение опыта женщин во всем мире.

${ }^{4}$ Лила Ганди (род. в 1966 г.) - известный ученый в области постколониальной теории, профессор гуманитарных наук и английского языка в Брауновском университете. Является правнучкой М. Ганди.

${ }^{5}$ Рэй Чау (Чоу) (род. в 1957 г.) - культурный критик, специализирующийся на китайской художественной литературе XX в., кино и постколониальной теории, профессор литературы в Университете Дьюка. Родилась и получила степень бакалавра в Гонконге, докторскую степень в области современной мысли и литературы получила в Стэнфордском университете.

${ }^{6}$ Элис Уокер (род. в 1944 г.) - афроамериканская писательница, феминистка, общественный деятель. В 1963 г. окончила колледж Сары Лоренс в Нью-Йорке, получив степень бакалавра искусств. В 1983 г. получила Пулитцеровскую премию в области художественной литературы за роман «Цвет пурпурный» (The Color Purple, 1982), экранизированный режиссером С. Спилбергом в 1985 г.

${ }^{7}$ Омолара Огундипе-Лесли (1940 - 2019 гг.) - нигерийская поэтесса, критик, редактор, одна из ведущих писательниц африканского феминизма. Родилась в Лагосе в семье педагогов и священнослужителей, стала первой женщиной, получившей степень бакалавра с отличием по английскому языку в Университетском колледже Ибадана, а затем в колледже Лондонского университета. В 1963 г. возглавила отдел феминистских и гендерных исследований в Африке.

${ }^{8}$ Обиома Немека (род. в 1948 г.) - профессор французского языка в Университете Индианы-Пердью Индианаполис нигерийского происхождения. Является автором теории него-фреминизма и основателем и президентом Ассоциации африканских женщин-ученых.

9 Термин «субалтерн» (subaltern) (буквально - «младший офицер») имеет военную этимологию, он был заимствован из «Тюремных тетрадей» А. Грамши. Используется для обозначения «малых социальных групп на краю истории» - притесняемых, маргинализированных социальных слоев населения, «неэлитарных» социальных классов. 
колоний. Проводя исследование угнетенных групп, Г. Спивак выдвинула проблему невидимости и неслышимости колонизированного населения, особенно женского. Именно с позиции женщин, как наиболее незащищенных и бесправных, она стремилась посмотреть на историю колониальных и постколониальных обществ.

Она задалась вопросом «Могут ли угнетенные говорить?» [4]. В тексте одноименного эссе 1988 г. Г. Спивак отмечала, что поэтапное движение угнетенных к освобождению осложняется на фразе империализма. Автор пришла к заключению, что «угнетенные не могут говорить [сами за себя], $<. .>$ проблема реабилитации и репрезентации угнетенных должна быть делом рук не их самих, а ученых, интеллектуалов» [4, р. 308], в том числе ее самой.

Притеснение женщины идеологами постколониального фреминизма рассматривается разносторонне как результат комплексного воздействия патриархальных традиций, экономических фракторов и расовых предрассудков. Дискриминация по признаку пола часто анализируется в контексте колониального угнетения.

Феминизм постколониальной волны базируется на утверждении, что женщины были маргинализованы патриархальным обществом и подвергались как общей дискриминации в качестве жителей колоний, так и индивидуальному давлению в условиях преобладания патерналистской культуры. Жеещины оказались бессильны не только перед системой, но и перед произволом, царящим в патриархальном доме и, соответственно, обществе [5, с. 34]. Подчиненное положение женщины афро-азиатского мира характеризует термин «двойная колонизация». Появление данного понятия связывают с работой Кирстен Холст Петерсен и Анны Резердрорд «Двойная колонизация: колониальное и постколониальное женское письмо» $[6]$.

Колониализм оказался тесно сплетен с патриархальной политической культурой, традиционно развивавшейся во многих африканских и азиатских государствах. Процесс деколонизации не означал конец угнетению женщин в бывших колониях. Постколониальные феминистки указывают на сохранение гендерных предубеждений и “двойной колонизации" в государствах, получивших независимость, и на то, что женщины продолжают подвергаться стереотипному восприятию и маргинализации [2, р. 95].

В условиях глобализации, интеграции, активизации мобильности гендерные вопросы стали более актуальной проблемой, чем когда-либо. Пересечение границы влечет за собой изучение "другого», но, что более важно, оно также должно повлечь за собой и обучение «у другого». Миграционные потоки, современная экономическая и оринансовая ситуация определили новые вопросы в рамках постколониальных исследований, такие как общая применимость феминистской теории во взаимосвязи национальности 
и пола в транснациональной парадигме, определение центра и периферии постколониального мира и другие.

Индийский фрилософр и феминистка Вандана Шива дала отрицательную оценку современным интеграционным процессам в мировой экономике, заявив, что женщины постколониальной эпохи подвергаются дискриминации на рынке труда и как представительницы Востока, и непосредственно как женщины [7, р. 97].

K теме двойной дискриминации обратилась Чандра Моханти в 1984 г. в эссе «Под западным взглядом: феминистская наука и колониальные дискурсы» [8]. Она отвергла понимание универсальности опыта, который предопределял навязывание женщине - жительнице колонизированного государства - моделей поведения, не присущих ее культурной традиции. В своей работе она ввела термин «женщина третьего мира» и описала сложившийся стереотип «среднестатистической женщины третьего мира» как невежественную, бедную, необразованную, связанную традициями и семьей, сексуально ограниченную жертву [8, р. 337]. Она подчеркнула, что создание образа «женщины третьего мира», всегда и везде угнетаемой, поддерживает иллюзию женщин «первого мира» о том, что они «светские, свободные и самостоятельно контролируют свою жизнью» [8, р. 353]. Ч. Моханти видела в глобализации обновленную по форме и содержанию колонизацию женщин и мужчин и призывала разработать механизмы коллективного сопротивления и освободительной стратегии.

Сложность и противоречивость процессов культурной идентификации обусловила необходимость учета постколониальных фракторов и различий женских постколониальных практик в современном мире. Позиции идеологов феминизма постколониальной волны во многом сходные, различаются по степени критичности в отношении оценки влияния западной культуры на традиционные общества и положение женщин в постколониальных странах. Нельзя не согласиться с Ч. Моханти в том, что «научный западный фреминистский дискурс и политическая практика не являются единичными и однородными по своим целям, интересам или анализу» [8, р. 334]. У женщин во всем мире сложился разный опыт в отношении постколониального наследия.

В противовес западному феминизму в оборот вводятся новые понятия, отражающие проблемы притеснения женщин в афро-азиатском мире. В 1980 г. в работе афроамериканской писательницы Элис Уокер впервые появился термин «вуманизм» (от англ. woman - женщина), характеризующий социально-фрилософркий комплекс идей, опирающихся на представление о расовом и гендерном угнетении чернокожих женщин [9]. Автор особо выделила преимущество использования данного понятия, не нуждающегося в добавлении определения «черный», поскольку оно подразумевалось по смыслу, в отличие от термина «феминизм», который без соответствующего уточнения воспринимался как «белый» - берущий начало в культу- 
Мильто А. В.

ре белых женщин [9, p. 100]. Для Э. Уокер вуманизм не просто делает акцент на расовых различиях, он подчеркивает разницу в ожиданиях белых и чернокожих женщин. Концепция Э. Уокер получила широкое признание среди афроамериканских женщин, что вызвало появление обновленных теорий, учитывающих непосредственно африканские особенности.

Профрессор Кленора Хадсон-Уимс ${ }^{10}$, автор теории африканского вуманизма (африкана-вуманизма), утверждала, что американские феминистские идеалы не распространяются на культурные интересы африканских женщин из-за продолжительной истории рабства и расизма в Америке [10, с. 110-111]. Вместо терминов «афроамериканец», «черный» или «африканец» она использовала более инклюзивное понятие «африкана» (africana), которое объединило африканцев, проживающих в Африке и диаспоре [11]. Она подчеркивала, что вуманизм отличается от всех феминистких движений тем, что у него другие приоритеты и «он сосредоточен на уникальном опыте, борьбе, потребностях и желаниях африканских женщин» [12].

Еще одну интерпретацию вуманизма представила нигерийская писательница Чиквенье Оконджо Огуниеми ${ }^{11}$. По ее мнению, африканский вуманизм, в отличие от феминизма и афроамериканского вуманизма, в меньшей степени индивидуален, сосредоточен на семье и коллективной борьбе африканцев за свои права в мировом сообществе [13]. «Черный вуманизм это фрилософия, которая прославляет черные корни, идеи черной жизни ... Его идеал - единство черных людей, где у каждого есть хотя бы капля власти и он может быть «братом», «сестрой», «отцом» или «матерью» для другого» $[14$, p. 68-69].

Новую альтернативу фреминизму предложила нигерийская писательница и поэтесса Омолара Огундипе-Лесли. В 1994 г. она представила миру стиунизм (stiwanism) - теорию, призывающую женщин к включению в процесс социальной трансорормации мира [15]. О. Огундипе-Лесли высказалась за активное участие женщин в преобразовании Африки в равноправном партнерстве с мужчинами с целью построения гармоничного общества. Со временем О. Огундипе-Лесли несколько переосмыслила свою концепцию в сторону радикализации, добавив идею борьбы женщин за свои права и смягчив свое отношение к феминизму [16, р. 242-244].

Исследователь и политический активист из Нигерии Кэтрин Обиануджу Ачолону ${ }^{12}$ противопоставила западному феминизму образ женщи-

${ }^{10}$ Кленора Хадсон-Уимс (род. в 1945 г.) - афроамериканская писательница, профрессор в Университете Миссури, автор теории африкана-вуманизма.

11 Чиквенье Оконджо Огуниеми (род. в 1932 г.) - нигерийская писательница, профессор литературы, основатель кафедры глобальных исследований Колледжа Сары Лоуренс (Нью-Йорк).

12 этрин Обиануджу Ачолону (1951-2014 гг.) - нигерийская писательница (игбо по происхождению), исследователь, политический активист. Была старшим специальным советником президента О. Обасанджо по вопросам искусства и культуры. В 1982 г. основала первый журнал, посвященный африканской литературе. 
ны-матери. В книге «Материзм - афроцентристская альтернатива фреминизму» она призывала к достижению женской свободы через проявление любви и заботы к своему ребенку, подчеркивая невозможность отделения вопросов материнства от африканской женщины. В отличие от западной женщины, которая вряд ли откажется от своей работы в пользу детей, африканская женщина не может жить без погружения в материнские хлопоты. Забота о ребенке позволяет ей выжить в патриархальном обществе. «Какой бы ни была роль Африки в глобальной перспективе, она не может быть отделена от <..> Материнского континента человечества, и не случайно материнство остается центральным направлением африканского искусства, африканской литературы...» [17, р. 3].

Нигерийско-американская писательница, профрессор Обиома Немека придерживалась мнения, что африканским женщинам присущ «него-фреминизм» (Nego-feminism). Него-фреминизм - это разновидность феминизма, основанная на культуре переговоров, а также теория, которая выступает за фреминизм «"без эгоизма” и модулируется с помощью растущих местных и глобальных потребностей» [18, р. 360-361]. В основе общих ценностей во многих африканских культурах, по мнению автора, «лежат принципы переговоров, взаимных уступок, компромиссов и баланса. <..> Для [африканских] женщин мужчина - это не «другой», а часть того же человека. Каждый пол представляет собой критическую половину, составляющую человеческое целое. Ни один из полов сам по себе не является полностью завершенным. Каждый имеет и нуждается в дополнении, несмотря на то, что обладает собственными уникальными особенностями. Африканские женщины <..> склонны работать с мужчинами для достижения поставленных целей. Готовность африканских женщин вести переговоры с мужчинами даже в трудных обстоятельствах широко распространена» [18, p. 379-380].

Оригинальное направление гендерного движения - арабский или мусульманский феминизм - базируется на признании незыблемости норм шариата. В условиях соблюдения исламских традиций, таких, например, как ношение хиджаба, он обычно вызывает недоумение у многих западных женщин. Они задаются вопросами: может ли мусульманка быть феминисткой, если скрывает лицо или делит мужа с тремя другими женами? Мусульманские женщины видят в исламе источник их религиозной идентичности, обеспечивающий им возможность реализовать свои женские потребности. Если западные фреминистки рассматривают хиджаб как символ подчинения и угнетения мусульманских женщин, то для исламских фреминисток хиджаб - символ исламской идентичности и освобождения от западного культурного влияния. Приверженцы исламского фреминизма призывают к равенству мужчин и женщин в личной и публичной сорерах и стремятся к пересмотру практик и толкований, которые оставляют жен- 
щину на вторых ролях, утверждая, что они противоречат предписаниям Корана [19, р. 13, 41].

Постколониальный феминизм объединил большое количество текстов, подходов и взглядов на стратегии освобождения женщин от угнетения и дискриминации. В эпоху глобализации, интеграции, транснационализации проявились стремления к универсализации направлений феминизма, без учета его исторической и географической специфики и способности продуктивно взаимодействовать с различиями; к выработке одного большого феминисткого течения, которое способно свести все или почти все потребности женщин в логическую глобальную практику, выходящую за рамки узких представлений о региональной или национальной культурах.

Однако игнорирование расовой и этнической принадлежности, исторического разнообразия и региональных особенностей зачастую приводит к обратному эффекту - желанию подчеркнуть свой уникальный опыт, что приводит к формированию локализации и изоляционизма [20, с. 156]. Современная постколониальная феминистская теория эклектична, поскольку ее идеологи по-разному реагируют на многообразие социальных, региональных и национальных особенностей. В настоящее время в отношении этой специфики тиражираются множественные подходы, взятые из разных дисциплин. Отсюда очевиден вызов политкорректности и вместе с ним западному научному сообществу, в силу чего происходят кумиризация и сакрализация инаковости, возврат к экзотизму.

«Женщины» не составляют единую группу исключительно по признаку пола. Статус и роли женщин варьируются в зависимости от сложного взаимодействия между такими фракторами, как этническая, социальная, культурная и религиозная принадлежности. Только глубокое осознание существования культурных различий, дифреренцированный анализ феминистских теорий, зависящий от контекста, учет опыта "другого» и разных жизненных историй позволят выработать эфрфективные политические стратегии и применить их на практике [8, р. 347].

\section{Ссылки}

1. Африка: постколониальный дискурс / отв. ред. Т. М. Гавристова, Н. Е. Хохолькова. М.: Институт Африки РАН, 2020. 248 с.

2. Ashcroft B., Griffiths G., Tiffin H. The Post-Colonial Studies: The Key Concepts. 2nd ed. L. \& N.-Y.: Routledge, 2007. 292 p.

3. Spivak G. C. French Feminism in an International Frame // Yale French Studies. 2013. N. 62. P. 154-184.

4. Spivak G. C. Can the Subaltern Speak? // Marxism and the Interpretation of Culture. L.: Macmillan Education, 1988. P. 271-313. 
5. Мильто А. В. Женское политическое лидерство в Сомали // Вестник Ярославского государственного университета им. П. Г. Демидова. Серия Гуманитарные науки. 2018. №1 (43). С. 29-34.

6. Holst-Petersen K., Rutherford A. A Double Colonization: Colonial and PostColonial Womens' Writing. Mundelstrup, Denmark; Oxford, England: Dangaroo Press, 1986. 188 p.

7. Shiva V. War against Nature and the People of the South // Views from the South: The Effects of Globalization and the WTO on the Third World / Ed. by S. Anderson. Chicago: IL USA, 2000. P. 91-125.

8. Mohanty C. Under Western Eyes: Feminist Scholarship and Colonial Discourses // Boundary 2. 1984. Vol. 12, No. 3. P. 333-358.

9. Walker A. Coming Apart // Take Back the Night: Women on Pornography / Ed. Laura Lederer. N.-Y.: W. Morrow, 1980. P. 95-104.

10. Хохолькова Н. Е. Афроцентризм в США: теория и практика социокультурных трансформаций. М.: Институт Африки РАН, 2019. 194 с.

11. Hudson-Weems C. Africana Womanism: Reclaiming Ourselves. 5th Edition. L.: Routledge, 2019. 176 p.

12. Russo S. Revue of the Womanist Reader by Layli Phillips // Feminist Teacher. 2009. Vol. 19, No. 3. P. 243-245.

13. Ogunyemi C. O. African Wo/Man Palava: The Nigerian Novel by Women. Women in Culture and Society. Chicago: University of Chicago Press, 1996. 366 p.

14. Ogunyemi C. O. Womanism: The Dynamics of the Contemporary Black Female Novel in English // Signs 11. 1985. № 1. P. 63-80.

15. Ogundipe-Leslie M. Re-creating Ourselves: African Women and Critical Transformations. Trenton, New Jersey: African World Press, 1994. 262 p.

16. Alkali M., Talif R., Wan Yahya W. R., Mohd Y. Dwelling or Duelling in Possibilities: How (Ir)relevant are African Feminisms? // GEMA Online® Journal of Language Studies. 2013. Vol. 13(3), September. P. 237-253.

17. Acholonu C. Motherism: The Afrocentric Alternative to Feminism. Owerri: Afa Publications, 1995. 144 p.

18. Nnaemeka O. Nego-Feminism: Theorizing, Practicing, and Pruning Africa's Way // Signs. 2004. Vol. 29, № 2. P. 357-385.

19. Moghadam V. M. Modernizing women: Gender and social change in theMiddle East. 2nd edition. Boulder, CO: Lynne Rienner Publishers, 2003. 300 p.

20. Гавристова Т. М. Нигерия - страна историй // Вестник Ярославского государственного университета им. П. Г. Демидова. Серия Гуманитарные науки. 2021. № 2 (56). C. $152-163$. 